Research Article

\title{
Lightweight Threshing Rack under Multisource Excitation Based on Modal Optimization Method
}

\author{
Haotian Zhang, Zhong Tang $\mathbb{D}^{D}$, Yu Li, Xin Liu, and Hui Ren \\ Key Laboratory of Modern Agricultural Equipment and Technology of Ministry of Education, Jiangsu University, \\ Zhenjiang 212013, Jiangsu, China \\ Correspondence should be addressed to Zhong Tang; tangzhong2012@126.com
}

Received 30 July 2020; Revised 6 November 2020; Accepted 4 December 2020; Published 14 December 2020

Academic Editor: Giorgio Pia

Copyright $(92020$ Haotian Zhang et al. This is an open access article distributed under the Creative Commons Attribution License, which permits unrestricted use, distribution, and reproduction in any medium, provided the original work is properly cited.

Crawler rice combine harvester threshing rack excited by different frequencies of multiple working parts would cause strong vibration response. In this paper, the rack-type rice combine harvester threshing rack was taken as research objective, and then the static analysis of the existing threshing rack was carried out by ANSYS Finite Element software. The topology of the rack structure was optimized according to the stress and strain distribution of the threshing rack. Based on solving the 6 natural frequencies and mode shapes of the threshing rack of combine harvester, the morphological test of threshing rack was carried out and the reliability of the modal analysis was verified. Finally, the multivibration source was assembled on the rack for simulation to test and verify the optimization effectiveness. Results showed that the 1st to 6th natural frequency of threshing rack after modal optimization could avoid the excitation frequency of the working part. Compared with the original design, the optimized threshing rack had a weight reduction of $13.7 \%$. This study can provide a theoretical reference for the structural design and optimization of combine harvester threshing rack.

\section{Introduction}

Rice is one of the three major food crops and the most important food crop in Asia. The rice production of China accounts for about $30 \%$ of world production [1]. With the improvement of mechanization of rice agriculture, rice combine harvesters have also been effectively promoted. However, there are multiple working parts on the combine harvester, which will result in a high quality of the whole machine. As an important load-bearing part of the whole machine, the threshing rack has a great influence on the working performance of the whole machine by its carrying capacity and the state when multiple parts work together. When the whole machine is running, the threshing rack will be excited by different working parts and cause strong vibration problems.

The threshing rack is bearing part of the mechanical structure. When multiple working parts on the rack are running, multisource excitation will be generated on the rack. At this time, the rack would strongly vibrate due to various excitation loads, which could cause the critical parts to be easily fatigued and damaged. As a result, it will affect the reliability and operation effect of the whole combine harvester. Therefore, in order to solve the problem that the rapeseed windrower caused the amplitude of the rack to be large due to the random excitation force generated by the movement of various components, Jiang et al. proposed an optimal design for increasing the structure of rack arch by establishing a Finite Element Model [2]. In order to solve the modal frequency and vibration mode of rapeseed windrower rack, the external vibration characteristics and simulation results of the rack were analyzed. Zhu et al. established the Finite Element Model of the rolling mill rack and simulated the connection relationship between various parts inside the rolling mill by means of node coupling to analyze the vibration characteristics of the rolling mill [3].

Resonance occurs at the natural frequency of the rack vibrating and overlapping with the external excitation frequency, which resulted in considerable deformation and dynamic stress of the rack structure and also caused destructive accidents. There are many studies on the vibration 
of agricultural machinery. Modal analysis method is also used to study the vibration characteristics of the rack. For example, Zhou et al. obtained the optimal design of the rack through the modal analysis and sensitivity analysis of ship tractor rack [4]. On the basis of only $2.4 \%$ increase in volume, the optimized rack modal frequency was far away from the working frequency of the engine. Guo et al. used HyperMesh and ANSYS software to carry out Finite Element Modal analysis of potato harvesting rack. They obtained the natural frequency and vibration mode in free state to analyze the influence of the operating frequency of the rack on the natural frequency [5]. Similarly, the dynamic characteristics of cold-formed racks by Finite Element and free modal analysis were carried out [6]. Fiebig et al. used a passive twostage vibration isolation system to reduce the vibration generated when the conveyor was working [7]. This system can significantly reduce the vibration propagation in the whole machine. Park et al. gave passengers an uncomfortable feeling about the vibration frequency of engine fans and other auxiliary components, when the vehicle was idling, and concluded that multifrequency vibration is more uncomfortable than single-frequency vibration by trial evaluation [8].

The natural frequency of the rack optimized by the Finite Element Mode can basically avoid the excitation frequency of the working component, which effectively avoids the resonance phenomenon. Zhang et al. obtained the Finite Element Modal analysis of the paper-yarn composite bag bottom machine rack; on this basis, the natural frequency and mode shape of the rack were solved, respectively. The low-order modal frequency of the rack avoided the external excitation source so that the operating frequency did not cause resonance [9]. Zhang et al. used ANSYS software to establish the Finite Element Model of rack and solved the 1st to 6th natural frequency and mode shape of the front rack. As a result, it is shown that the natural frequency of the rack could be within normal working conditions, which could avoid the excitation frequency of field pavement and vibrating screen [10]. However, there is less research on the rack of crawler type rice combine harvester at present. Considering the fact that the combined harvester threshing rack carries more key working parts, there is often a strong vibration response caused by different frequency excitation. Therefore, it is urgent to solve the vibration response problem when the rack is undergoing multiple excitation sources.

This paper performed ANSYS-based static analysis and topology optimization on the crawler rice combine harvester threshing rack and modal analysis on the structure. The optimized results were manufactured into products to compare the calculated modal and experimental modal errors. Then the natural frequency of threshing rack was compared with the excitation frequency. The threshing rack was subjected to various rotational frequency excitations during the working process of the harvester. The optimization results were verified after assembly, and then the scheme was analyzed and compared to avoid resonance.

\section{Materials and Methods}

2.1. Combine Harvester Threshing Rack. The main function of combine harvester threshing rack is to carry a plurality of working parts, such as harvester threshing fan, cleaning sieve, cutting longitudinal flow cylinder, crushing groove, partial bearing, and baffle, which will produce multisource excitation to the rack when working. The threshing rack assembling the multisource excitation structure was shown in Figure 1.

Threshing rack is mainly composed of a longitudinal flow beam, a left beam and a right main beam, a front beam, and an auxiliary beam. The main beam, the front beam, and the left and right main beams are the main load-bearing structures. Auxiliary beam mechanism is a stable structure of threshing rack for the transmission of bearing capacity. Combine harvester threshing machine rack structure was shown in Figure 1. In this paper, the crawler combine harvester threshing rack was used as research objection. The fuselage data required for dismantling and mapping of the harvester was performed. Then, a series of measurements and calculations were performed on the harvester body parts.

According to the related research on the structure of existing longitudinal flow combine harvester [11], this paper selected the rice combine harvester with the feeding rate of $6 \mathrm{~kg} / \mathrm{s}$. The transmission principle of multisource excitation assembly part and rotating speed and transmission ratio of each moving part is shown in Figure 2.

The parameter of each working part of the transmission system was set by combining the above work plan and the operating parameters of the crawler combine harvester. The working speed of the combine harvester can be reduced to $80 \%$ of the designed speed during the working process, so that the reference frequency and the excitation frequency range during operation could be calculated with the main working parameters of the combine harvester. The main motion parameters and fundamental frequency of the combine harvester threshing device are shown in Table 1.

As is shown in Table 1, the vibration excitation frequency of the vibrating screen and the returning plate of the combine harvester was $5.78 \sim 7.22 \mathrm{~Hz}$. Excitation frequency of the auger of the header was $10.94 \sim 21.12 \mathrm{~Hz}$. The excitation frequency of the longitudinal flow roller was $7.46 \sim 13.17 \mathrm{~Hz}$; and the excitation frequency of the transmission input shaft and fan shaft was $14.24 \sim 20.10 \mathrm{~Hz}$. The load on the threshing rack was composed of two aspects, which contains the gravity of threshing rack and the weight of rack itself by the various working parts on the threshing rack. The rotary shaft of each working part was mounted on the threshing rack through the bearing housing. According to the static equivalent principle, the working parts will act on the threshing rack in a concentrated or uniform load.

The static load applied by the working part to the threshing rack is divided into point load and surface load. The equation for calculating the static point load is as follows: 


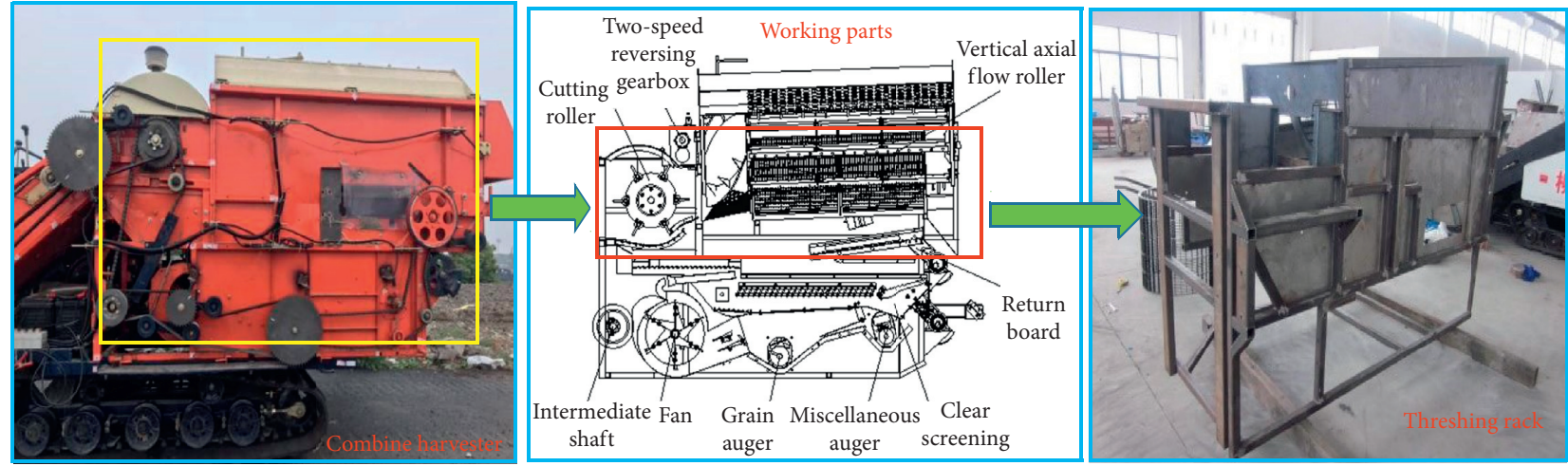

Figure 1: The threshing rack assembling the multisource excitation structure.

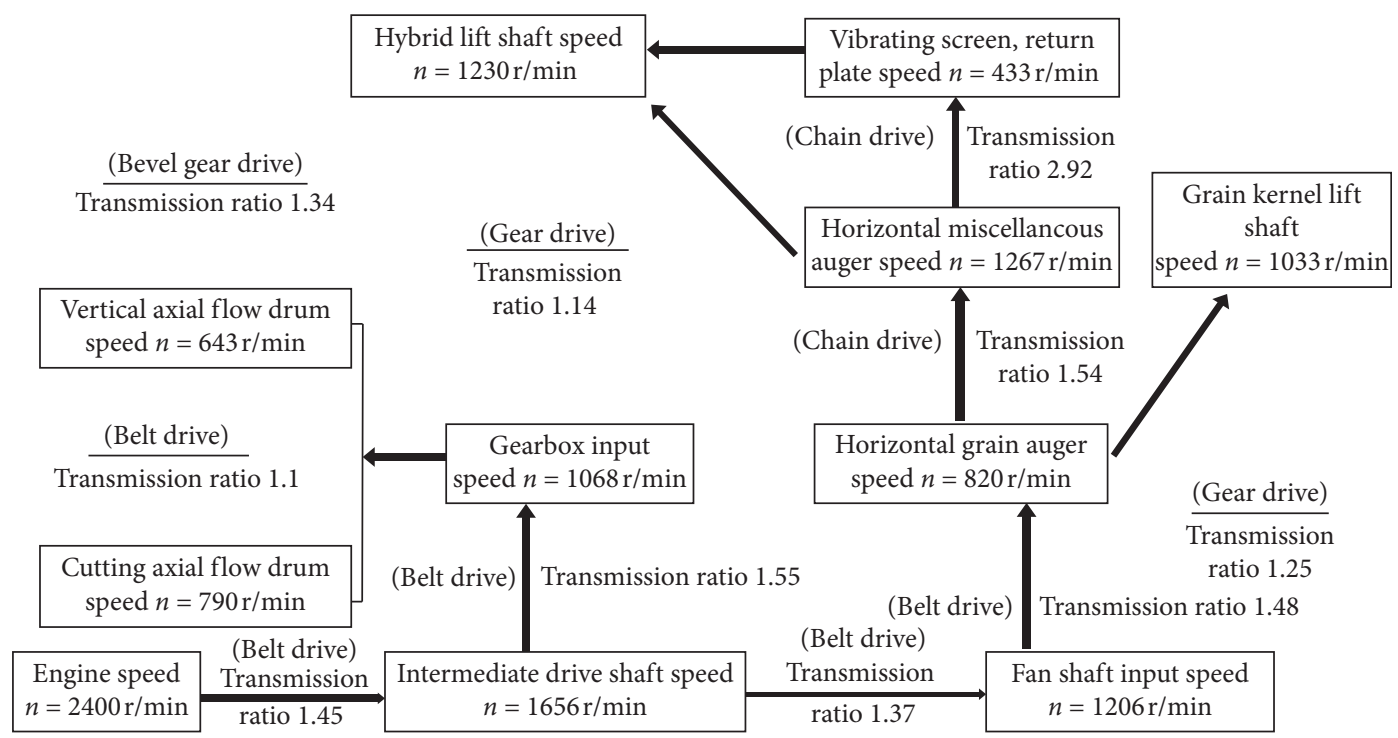

FIGURE 2: Working parameters and transmission principle of multisource excitation assembly on combine harvester.

TABLE 1: Working frequency of main transmission parts of combine harvester.

\begin{tabular}{|c|c|c|c|c|}
\hline Working part & $\begin{array}{l}\text { Rotating speed } \\
\left(\mathrm{r} \cdot \mathrm{min}^{-1}\right)\end{array}$ & $\begin{array}{l}\text { Transmission } \\
\text { form }\end{array}$ & $\begin{array}{l}\text { Reference frequency } \\
(\mathrm{Hz})\end{array}$ & $\begin{array}{l}\text { Operating frequency range } \\
(\mathrm{Hz})\end{array}$ \\
\hline Gearbox input shaft & 1068 & Belt drive & 17. 80 & $14.24 \sim 17.80$ \\
\hline 1st gear cutting roller & 790 & Belt drive & 13. 17 & $10.54 \sim 13.17$ \\
\hline 2nd gear cutting roller & 687 & Belt drive & 11. 45 & $9.16 \sim 11.45$ \\
\hline 1st gear vertical axial flow roller & 643 & Gear drive & 10. 72 & $8.578 \sim 10.72$ \\
\hline $\begin{array}{l}2 \text { nd gear vertical axial flow } \\
\text { roller }\end{array}$ & 559 & Gear drive & 9. 32 & $7.46 \sim 9.32$ \\
\hline Fan shaft & 1206 & Belt drive & 20. 10 & $16.08 \sim 20.10$ \\
\hline Grain agitator shaft & 820 & Belt drive & 13. 67 & $10.94 \sim 13.67$ \\
\hline Miscellaneous agitator shaft & 1267 & Chain drive & 21. 12 & $16.9 \sim 21.12$ \\
\hline Vibrating screen & 433 & Chain drive & 7. 22 & $5.78 \sim 7.22$ \\
\hline Return board & 433 & Chain drive & 7. 22 & $5.78 \sim 7.22$ \\
\hline
\end{tabular}

$$
P=\frac{m g}{n}
$$

where $P$ is the surface load, $\mathrm{N} ; m$ is the mass, $\mathrm{kg} ; g$ is the acceleration of gravity, $9.8 \mathrm{~m} / \mathrm{s}$; and $n$ is the number of support points. follows:

The equation for calculating the static surface load is as

$$
P=\frac{m g}{s},
$$

where $P$ is the surface load, $\mathrm{Pa} ; m$ is the mass, $\mathrm{kg} ; g$ is the gravitational acceleration, $9.8 \mathrm{~m} / \mathrm{s}^{2}$; and $s$ is the force area, $\mathrm{m}^{2}$.

The load applied to the rack by the various working parts of the combine harvester threshing device is shown in Table 2. 
TABLE 2: Working part load value of combine harvester threshing rack.

\begin{tabular}{lcccc}
\hline Serial number & Load name & Mass of working part $(\mathrm{kg})$ & Load value & Loading method \\
\hline 1 & Cutting roller & 46 & $450.8 \mathrm{~N}$ & Concentrated load \\
2 & Cut flow cap & 13 & $1851.9 \mathrm{~Pa}$ & Uniform load \\
3 & Intermediate shaft & 26 & $264.6 \mathrm{~N}$ & Concentrated load \\
4 & Vertical axial flow roller & 78 & $764.4 \mathrm{~N}$ & Concentrated load \\
5 & Vertical axis top cover & 60 & $1.0 \times 10^{6} \mathrm{~Pa}$ & Uniform load \\
6 & Vertical axis flow concave screen & 40 & $5681.2 \mathrm{~Pa}$ & Uniform load \\
7 & Clear screening & 100 & $980.0 \mathrm{~N}$ & Concentrated load \\
8 & Threshing cleaning rack & 20 & $2557.8 \mathrm{~N}$ & Inertial load \\
9 & Fan & 261 & $196.0 \mathrm{~N}$ & Concentrated load \\
10 & Header and trough & 470 & $4606 \mathrm{~N}$ & Concentrated load \\
11 & Grass mower & 97 & $950.6 \mathrm{~N}$ & Concentrated load \\
12 & Grain auger & 50 & $490.0 \mathrm{~N}$ & Concentrated load \\
13 & Miscellaneous auger & 44 & $431.2 \mathrm{~N}$ & Concentrated load \\
14 & Transmission case & 48 & $470.4 \mathrm{~N}$ & Concentrated load \\
\hline
\end{tabular}

2.2. Finite Element Modeling and Meshing. In order to achieve optimization and modal analysis of the threshing rack, Finite Element Modeling was an important method [12]. In this paper, Pro/E was used to establish the threedimensional model of threshing rack. The mechanical structure of the threshing rack is mainly made of square steel, rectangular steel, and bent plates. Threshing rack was divided into different submodules before virtual assembly, which contained intermediate shaft bearing rack, cutting roller bearing rack, vertical axial flow roller bearing rack, cleaning sieve bearing rack, fan bearing rack, auger bearing rack, and chassis carrying rack. On this basis, the components of the corresponding submodule were drawn, and the virtual assembly of the threshing rack was performed from bottom to top through Pro/E [13]. Considering that the rack material of general agricultural machinery is usually selected from Q235 steel which is low in price and easy to process and repair, the threshing rack of this paper was made of Q235A semiforked steel whose thickness was $5 \mathrm{~mm}$ [14]. The material properties are shown in Table 3.

The Finite Element Method is used to express a continuous combination with a finite number of elements, so that an infinite degree of freedom problem becomes a finite degree of freedom problem. Before rack modal analysis, the rack needs to be meshed to form a unit with a finite number of nodes. Grids of different sizes and shapes have an important impact on the analysis results [15].

The meshing platform in the Finite Element analysis software can automatically perform meshing according to the structure and characteristics of the object. It has a variety of methods to divide the meshing platform [16], such as automatic, tetrahedrons, and hex-dominant. If the solid model was used to divide the grid, considering the complex structure of the threshing and cleaning rack, the calculation scale would be very large, which far exceeded the computing power of the existing computer in the laboratory. Therefore, automatic meshing was used to balance calculation accuracy and calculation time. The divided grid had 161,722 nodes and 66,663 elements [17], which was shown in Figure 3.

In order to improve the accuracy and uniqueness of the Finite Element simulation analysis results, the threshing rack
TABle 3: Property values of rack materials.

\begin{tabular}{lccc}
\hline Serial number & Attribute name & Numerical value & Unit \\
\hline 1 & Elastic modulus & $206 \times 10^{9}$ & $\mathrm{~Pa}$ \\
2 & Poisson's ratio & 0.30 & - \\
3 & Density & 7800 & $\mathrm{~kg} / \mathrm{m}^{3}$ \\
4 & Yield strength & $235 \times 10^{6}$ & $\mathrm{~Pa}$ \\
5 & Strength limit & $(375 \sim 500) \times 10^{6}$ & $\mathrm{~Pa}$ \\
\hline
\end{tabular}

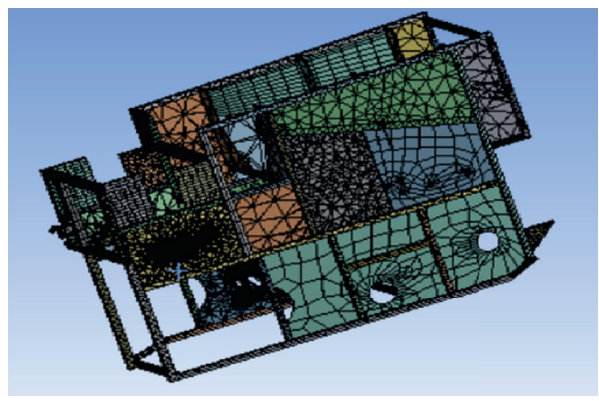

FIGURE 3: Threshing rack after dividing the grid.

strength matrix was set to a nonsingular value. The calculation results of the Finite Element simulation were effectively improved by setting the correct constraints. The threshing rack of the combine harvester studied in this paper was fixed on the bottom frame by bolts to prevent it from swinging sharply during the working process. Therefore, the bottom of the threshing and cleaning rack was set as a fixed constraint. The degree of freedom of the structural unit is restricted by controlling the degree of freedom in the $X, Y$, and $Z$ directions [18]. In order to solve the stress and strain situation of the threshing rack in the actual load-bearing process, the load of the main working parts of the threshing rack was applied to the Finite Element Model of the threshing rack in ANSYS to simulate the load of the threshing rack. As described above, the magnitude of the load applied to the threshing rack by the working member was obtained by weighing and calculating, which was shown in Figure 4. 


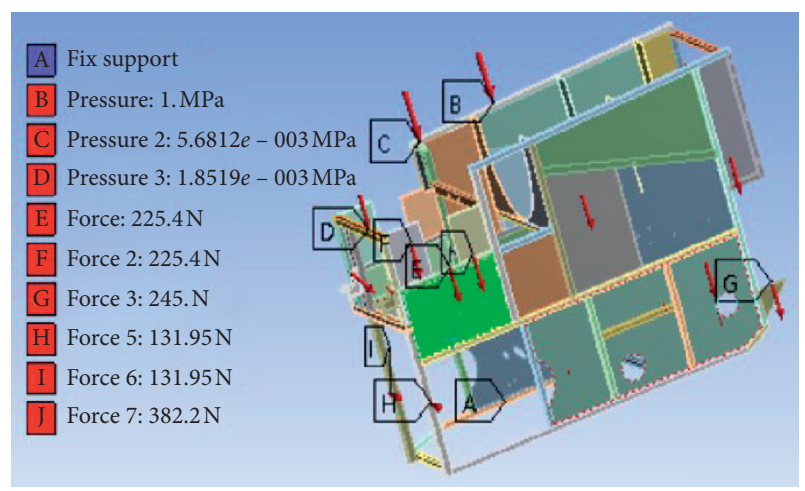

FIgURE 4: Threshing cleaning rack loading diagram.

2.3. Topology Optimization. Structural topology optimization is an optimization method that maximizes the removal of mechanical materials in the redundant areas of strength to achieve predesigned weight reduction targets [19]. It is necessary to determine the force of the mechanical structure before the topology optimization design and to clearly optimize the size of the target. Then the constraints can be set to optimize the topology of the mechanical structure. The mathematical model of topology optimization can be expressed as follows:

$$
\begin{aligned}
\min F(x) & =F\left(x_{1}, x_{2}, \ldots, x_{n}\right), \\
g_{i}(x) & =g_{i}\left(x_{1}, x_{2}, \ldots, x_{n}\right), \quad i=1,2, \ldots, M, \\
X & =\left(x_{1}, x_{2}, \ldots, x_{n}\right)^{T},
\end{aligned}
$$

where $F(x)$ is the objective function of the design variable; $X$ is the design variable; and $g_{i}(x)$ is the state variable. The rack must ensure sufficient strength during operation, and the fourth strength theory is used to constrain the stress of the whole machine.

$$
\sigma_{\max }(k)<[\sigma]
$$

where $\sigma_{\max }(k)$ is the equivalent stress, MPa; $[\sigma]$ is the allowable stress value of the material, and the profile material is Q235A steel, so $[\sigma]=195 \mathrm{MPa}$.

The optimization goal of the model is to minimize mass when the requirements of the rack strength are met [20], so the size optimization objective function is as follows:

$$
M(x)=V(x) \cdot \rho,
$$

where $V(x)$ is the volume, $\mathrm{m}^{3}$; and $\rho$ is the density, $\mathrm{kg} / \mathrm{m}^{3}$.

While optimizing the design of the rack, its corresponding strength and stiffness requirements must be met. Therefore, the purpose of topology optimization in this paper was to optimize and reduce weight on the premise that the entire threshing rack met the previous statics requirements. The module used in this paper was the built-in topology optimization module in ANSYS Workbench Toolbox. The module was connected with the analysis result of statics as the limiting condition for the topology optimization of the whole threshing rack. The stress and strain generated by each force and pressure were state variables; since the material of the threshing frame is Q235, the upper limit of the stress is $195 \mathrm{MPa}$. Each supporting beam and connecting plate that were not directly subjected to force can be used as design variables for optimization; the objective function was the flexibility of the threshing frame, that is, the displacement caused by unit force to characterize the stability of the system. Under the premise of ensuring that the stress and deformation of the entire rack met the requirements, the weight was reduced. The response limit condition of topology optimization was that the weight of the threshing rack was reduced by $15 \%$.

2.4. Modal Analysis of Optimized Rack. When modal analysis is carried out on the threshing rack of the harvester, the influence of vibration is mainly considered from the perspective of the overall structure of the rack. The vibration generated by the rack is caused by the excitation of the rotating parts and the engine. If the structural design is not ideal, the rack will be deformed with great torsion, bending, and so forth and even cause breakage and fatigue damage. The modal analysis is the process of calculating the natural frequency of the chassis rack and its corresponding modal shape, which is essentially the calculation of the eigenvalues of the feature vector and structural vibration [21].

By introducing the inertial force into the optimized threshing rack, the equilibrium equation is listed as follows:

$$
M \alpha+B v+K x=A(t)+Q
$$

where $M$ is the mass matrix; $\alpha$ is the acceleration vector; $B$ is the damping matrix; $v$ is the velocity vector; $K$ is the stiffness matrix; $x$ is the displacement vector; $A(t)$ is the external force function vector; and $Q$ is the boundary constraint reaction force vector.

Solve the natural frequency and mode shape of the system in the case of ignoring damping and external loads. Then the equation is as follows:

$$
M \alpha+K x=0 .
$$

Decompose the vibration into a series of simple harmonic vibrations according to the free vibration theory of the elastic body. The displacement corresponding to the simple harmonic motion is a sine function: $x=U \sin (\omega t)$. Then the equation is as follows:

$$
K-\omega_{i}^{2} M \Phi_{i}=0,
$$

where $\Phi_{i}$ is the node displacement amplitude vector, that is, the natural mode shape of the system structure; $\omega_{i}^{2}$ is the generalized eigenvalue; $i$ is the degree of freedom; $\omega_{i}$ is the natural frequency.

Because $\Phi_{i}$ of equation (8) is a nonzero vector, the determinant $\left|K-\omega_{i}^{2} M\right|$ should be equal to 0 , which is used to calculate the nonzero solution of the equation. According to the generalized eigenvalue equation theory, when the structural system is discrete and has $n$ degrees of freedom, the stiffness matrix and the mass matrix can be obtained as well as the $n$-order matrix. Solving equation (8) can calculate the $n$-order natural frequency of the elastic body and the corresponding mode shape. 
The experimental modal analysis is the same as the computational modal analysis [22], which is also to analyze the vibration characteristics of the structure and determine the natural frequency and mode shape of the structure. The difference is that the experimental modal analysis is to stimulate the physical structure through the hammer, and, at the same time, the structural response is collected and the modal parameters of the system structure were finally obtained through the data processing. Through this method, the modal parameters of the structure are obtained and then compared with the simulation analysis results to verify the accuracy of the Finite Element simulation model.

Before the test modal analysis, the first step was to establish a test modal test system to acquire a more accurate response signal and accurately determine the modal parameters of the structure. The test modal analysis was roughly divided into five steps (pretest analysis, establishment of modal model, data acquisition, parameter identification, and result verification). The test modal test system generally consists of an exciting hammer, a test mechanism, a data acquisition system, and a modal analysis system. The force hammer used in the modal analysis was the force hammer exciter produced by PCB Company of America. The signal acquisition instrument model was DH5902. The sensor was a PCB three-way acceleration sensor. Data acquisition can collect signals of 12 measuring points at a time. The specific test modal acquisition equipment parameters were shown in Table 4 and Figure 5.

The measuring point is both the selection point of the excitation signal input and the selection point of the response signal output. Measuring point position and number of measuring points can show the vibration mode change of the rack test mode. It also collects the response signal more effectively, which helps to analyze the natural frequency and mode shape of the rack [23]. Generally, when arranging the measuring points of the rack, the following principles should be as follows.

The position of the measuring point should avoid the position of the rack node, because the signal acquisition system is difficult to collect the response signal at the node. It is necessary to weigh the accuracy and efficiency of the test results and the scientific and rational arrangement of the number of measuring points. Because an excessive number of measuring points can more accurately represent the mode shape change of the mode and also increase the workload and software computing scale, it is necessary to arrange measuring points on each structure so that the measuring points can faithfully display the shape characteristics of the rack. In addition, add more points to the position where the vibration mode changes.

Combine the calculated modal shape pattern and measuring point arrangement principle of the completed threshing rack to make the measuring point arrangement of the rack. Finally, a total of 120 measuring points were arranged on the optimized threshing and cleaning rack, as shown in Figure 6.

The excitation point is where the excitation signal is input, and the placement of its location is also critical. The choice of incentive point location has the following main principles. The position of the excitation point should avoid the node because the response signal at the node is 0 . The position of the excitation point is generally selected to be more rigid. Priority is given to the location of the excitation point that motivates the modal parameters of more test bands. The selected incentive point is to facilitate the completion of the manual tap action. The single-point excitation and multipoint response method were used to collect the response signal of the rack. There were three measuring points for collecting response signals. The specific location selection of the excitation point was shown in Figure 7.

The results obtained by simulation modal analysis and test modal analysis will be somewhat different. The results obtained by simulation modal analysis and test modal analysis will be different to some extent, because there are some interference factors in the two analysis methods, which will affect the accuracy of the results. The Finite Element software does not consider the damping problem of the mechanical structure at analyzing the modality. The same test modal analysis will also have uncertain interference factors. For example, when striking a mechanism with a hammer, there is no guarantee that each tap is effective. Now the relevance of the two should be analyzed. The error rate is calculated as follows:

$$
\Delta f=\frac{f_{A}-f_{T}}{f_{A}} \times 100 \%,
$$

where $f_{A}$ is the Finite Element Modal analysis natural frequency; $f_{T}$ is the modal test natural frequency. The error rate is within $8 \%$ and the natural frequencies obtained by the two modal analyses are considered to be consistent [24].

\section{Results and Discussion}

3.1. Stress and Strain Distribution. The Finite Element static analysis is mainly used to analyze the deformation and equivalent stress of the optimized threshing rack after being loaded. According to the total variables and equivalent stresses on the obtained cloud map, whether the bearing capacity of each part of the threshing rack meets the requirements is analyzed. The structural optimization control rack mode can be performed in the place where the carrying capacity is relatively abundant. After completing all the preprocessing, ANSYS Workbench Toolbox will automatically calculate the deformation and stress distribution of the rack. The equivalent stress and total deformation of the rack were shown in Figures 8 and 9, respectively.

As can be seen from Figure 8, the maximum equivalent stress was $158 \mathrm{MPa}$, which was less than the yield strength of Q235A. Taking into account the working conditions and reliability of the threshing rack, the safety factor is usually 1.2 when designing the threshing rack, and the allowable stress value is $[\sigma]=\sigma b / n=195 \mathrm{MPa} ; \sigma_{\max }=170.82 \mathrm{MPa}<[\sigma]$. It was calculated that the maximum equivalent stress of the threshing rack is less than its allowable stress, which was in accordance with the stiffness and strength conditions [25]. The stress value of each main component of the entire frame 
TABLE 4: Equipment and quantity required for modal test.

\begin{tabular}{lcccc}
\hline Serial number & Equipment & Quantity & Parameter & Use \\
\hline 1 & Hammer & 1 & $\begin{array}{c}\text { Model: 086C03 } \\
\text { Model: 356A24 } \\
\text { Output signal: analog type } \\
\text { Material: metal }\end{array}$ & Pulse excitation signal \\
2 & 3-way acceleration sensor & 9 & $\begin{array}{c}\text { Number of input channels: } 36 \\
\text { Input method: ICP input } \\
\text { Sampling accuracy: } 130 \mathrm{~dB}\end{array}$ & Data signal acquisition \\
3 & Data collection system & 1 & Model: DHDAS & Analysis of modal parameters \\
5 & Modal analysis software & 1 & - & Calculating modal parameters \\
6 & Computer & 1 & - & Passing data
\end{tabular}

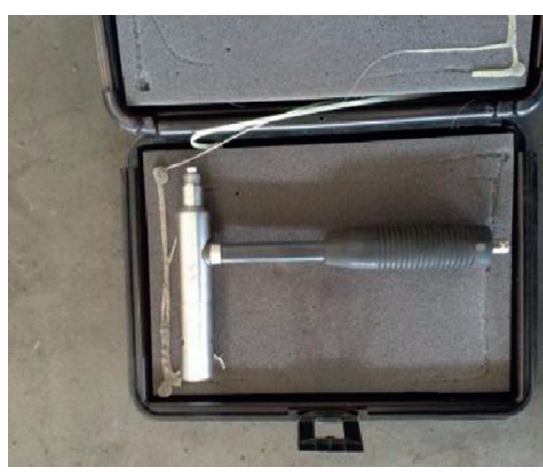

(a)

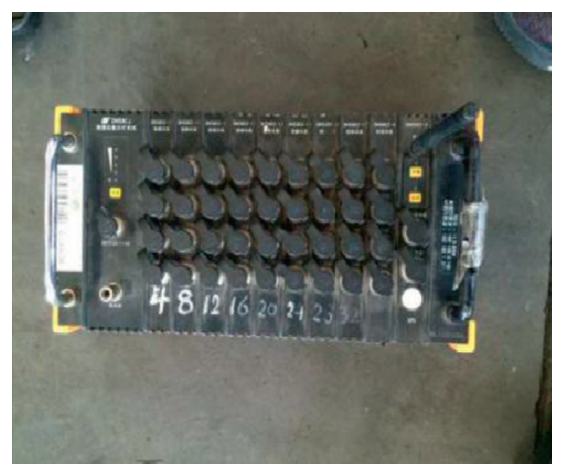

(b)

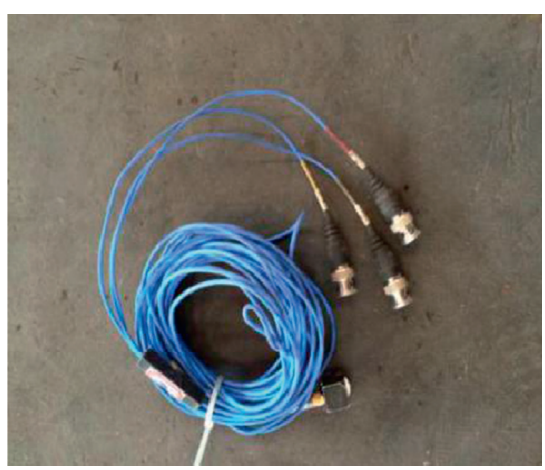

(c)

FIGURE 5: Test equipment required for modal test. (a) Hammer. (b) Data collection system. (c) Signal transmission data line.

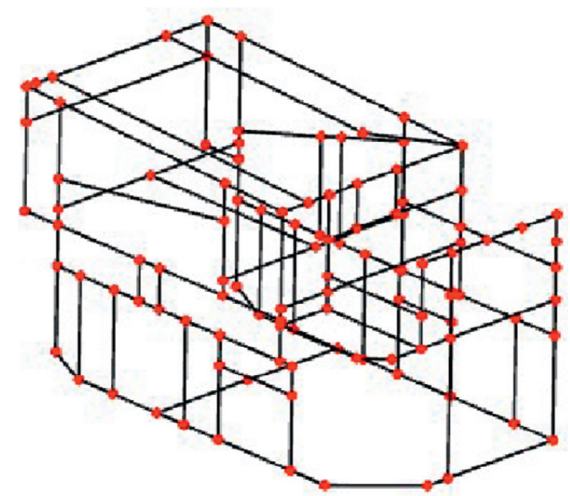

FIGURE 6: Measuring point position.

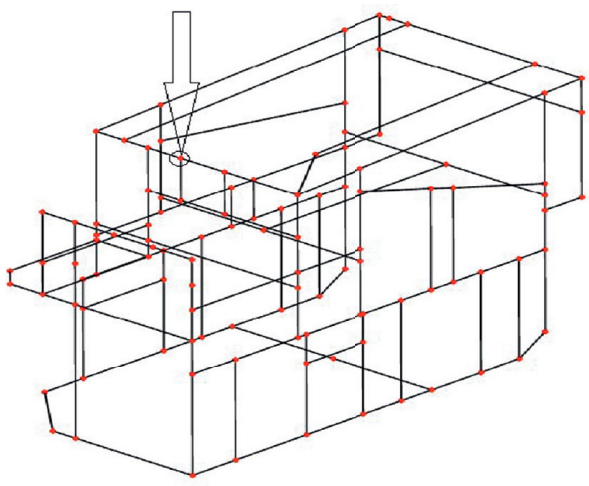

FIGURE 7: Location of incentive points.

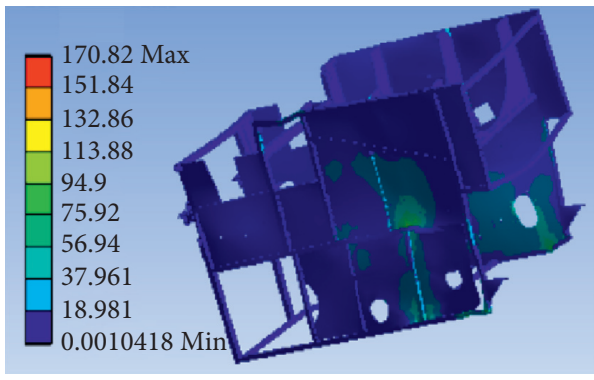

FIgURE 8: Equivalent stress.

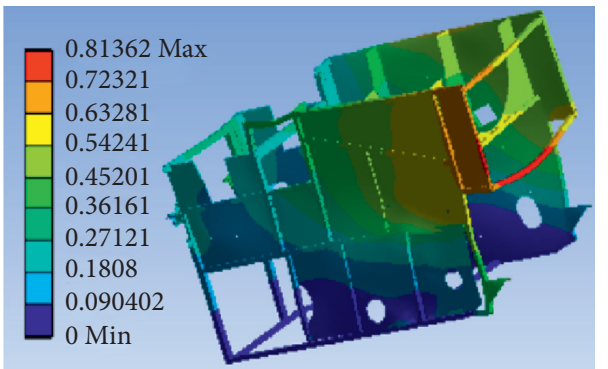

FIgURe 9: Maximum deformation cloud. 
is far less than the maximum value, so the structure fully meets the load-bearing requirements, and the structure and size can be further optimized to effectively reduce the cost. As shown in Figure 9, the maximum equivalent strain solution was $0.81 \mathrm{~mm}$, which was distributed on the support beam of the longitudinal axial flow cylinder.

3.2. Threshing Rack Optimization and Improvement. Topology optimization refers to a mathematical method for optimizing material distribution in a given area according to given load conditions, constraints, and performance indicators. Topology optimization includes size optimization and shape optimization. It is an effective means to determine the initial configuration of the product at the initial design stage of the product. Ghasemi et al. present a design methodology based on a combination of isogeometric analysis (IGA), level set, and pointwise density mapping techniques for topology optimization of piezoelectric/ flexoelectric materials. The accuracy of the IGA model is confirmed through numerical examples; on this basis, topology optimization was used to demonstrate the significant enhancement in electromechanical coupling coefficient that can be obtained [26]. Furthermore, they presented a computational design methodology for topology optimization of multimaterial-based flexoelectric composites. The multiphase vector level set (LS) model was adopted to avoid overlapping or vacuum among different phases [27]. These studies provide important methods reference and research basis for the optimization of composite materials.

The use of topology optimization design methods in agricultural machinery has greatly improved the efficiency of lightweight design and maximized material savings. During the optimization, the result of the objective function of the whole rack after 9 iterations of optimization tends to 0 , reaching the upper limit of iteration. It can be seen from Figure 10 that when the number of iterations exceeds 6 times, the optimization result does not meet the actual flexibility requirements. Since the limitation of topology optimization was $15 \%$ reduction in mass, the mass percentage curve after iteration was shown in Figure 11. It can be seen from Figures 10 and 11 that, after one iteration, the quality of the whole rack was reduced by $15 \%$. In this state, the flexibility of the threshing rack basically did not change; therefore, after the structural topology optimization, the strength of the threshing rack was not reduced. The quality of the rack after optimization was reduced by $15 \%$. However, in the actual design of the threshing and cleaning rack, the stress and strain distribution problem, the structural stability problem, and the layout of the working parts are required to be comprehensively considered. The red part of the rack was not necessarily removed [28]. Maximizing the lightweight design of the rack to meet strength and stiffness is also a validation of topology optimization results.

On the premise of this principle, rack structure topology optimization and optimized rack three-dimensional map were shown in Figure 12. The removed area is some material that can be removed. The marginal area is a self-processing area, which is removed or retained according to actual

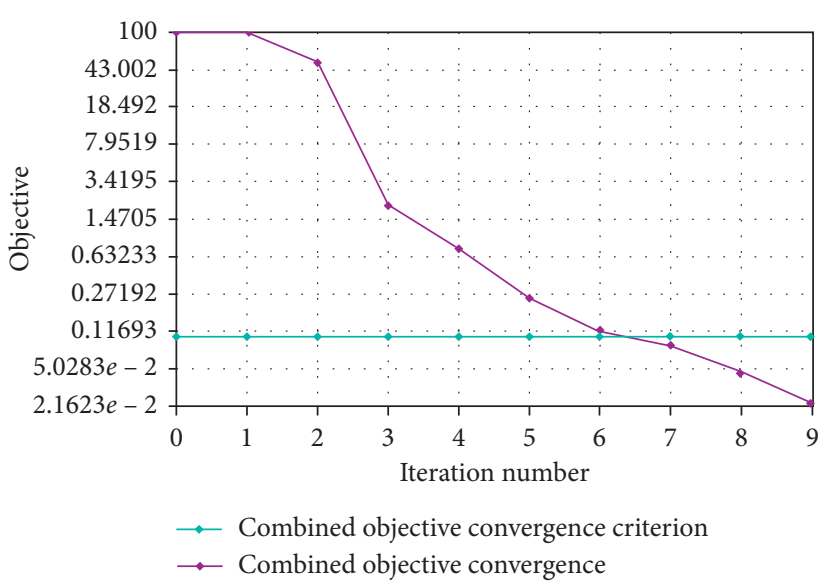

FIgURE 10: Objective iteration result.

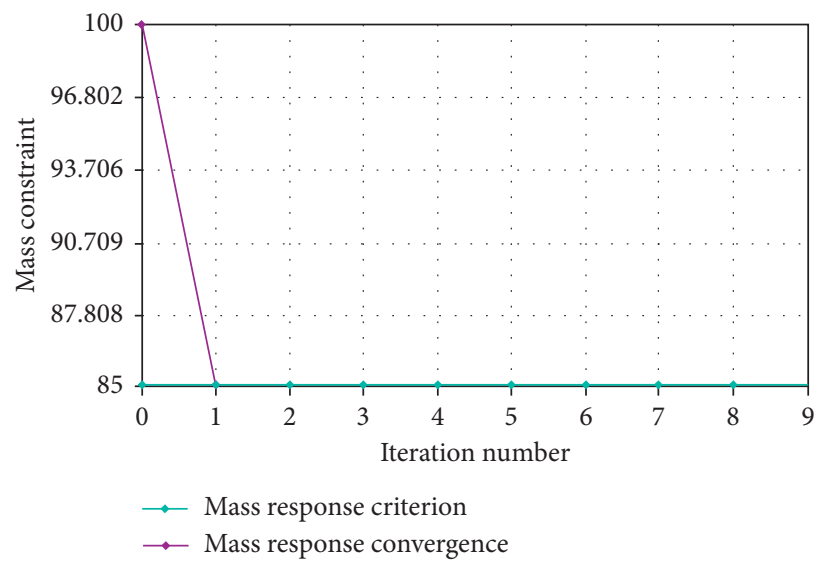

Figure 11: Constraint iteration result.

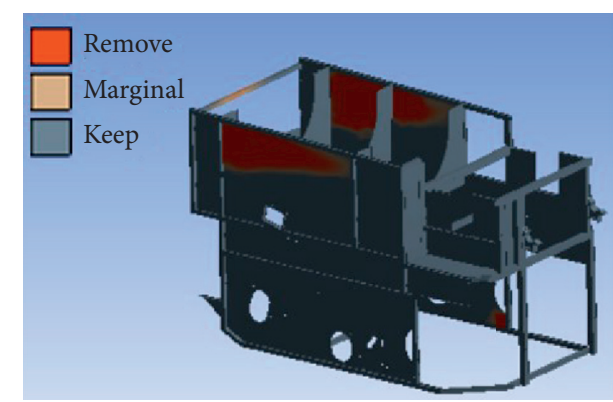

FIGURE 12: Rack structure topology optimization.

conditions, and then the keep area is an area where material is to be retained. It can be seen from Figure 12 that the baffle part at the threshing rack was an excess component. Considering that a baffle should be used at this position to prevent material from being thrown out during the actual machine working process, the thickness of the baffle at this position was changed from $1.5 \mathrm{~mm}$ to $0.2 \mathrm{~mm}$ instead of removing the part in the actual design optimization result. In addition, in order to increase the load-bearing capacity of the 
rack and increase its natural frequency, the rear beam was changed to a thin plate and reinforced by two beams.

The specific optimization plan was as follows: (1) Remove the original side mounted gearbox and design a two-speed reversing gearbox between the choke roller and the longitudinal axial roller. (2) Thereby, the rack supporting the original transmission case at the side was removed, and the rack at the front end of the longitudinal axial flow cylinder was reinforced. According to the working performance and working flow of the working part of the threshing device, the vertical axial flow cylinder placed horizontally was designed as a vertical axial flow cylinder placed obliquely. Redundant secondary cleaning was added in the original working flow, that is, return board working part. Therefore, the main beam of the original horizontal support longitudinal cylinder was designed as an inclined support. The part of the rear end of the rack where the returning board is installed was also strengthened. According to the data of the topology optimization, the square steel and the rectangular steel with the excess strength were designed as the bending plates of the same strength. The parts welded together by the multiple parts were designed as one integral part. The improved model after topology optimization was shown in Figure 13.

\subsection{Simulation and Test Modal Comparison. Since the modal} analysis process does not consider external loads and boundary conditions, the Finite Element analysis model of the rack was subjected to modal analysis and extraction in a free state. Many methods are embedded in ANSYS/Workbench software, including subspace method, Block Lanczos method, and reduced method. Considering that the Block Lanczos method has the advantages of fast convergence speed and high accuracy, this paper chooses the Block Lanczos method to extract the modal parameters. According to vibration theory, resonance is mainly caused by inherent low frequency [29], so the first 6 modes of threshing racks are mainly analyzed. Combined with the simulation animation processing of the vibration mode in the results, the characteristics of each mode shape can be clearly understood. The natural frequency and mode shape of the first 6 modes were shown in Figure 14.

The following results were obtained by analyzing the 6thorder mode shown in Figure 14. The first-order modal frequency was $16.476 \mathrm{~Hz}$, and bending of longitudinal axial flow cylinder beams was main characteristic of the mode; the second-order modal frequency was $27.913 \mathrm{~Hz}$, and the main mode was the bending of tangential flow cylinder and longitudinal axial flow cylinder beam. The third modal frequency was $35.426 \mathrm{~Hz}$, and the mode shape was the bending of the top of the threshing frame; the fourth mode frequency was $45.523 \mathrm{~Hz}$, and the main mode was the combination of bending and torsion on the top of the threshing frame; the fifth mode frequency was $56.366 \mathrm{~Hz}$, and the vibration shape was the torsion of the longitudinal axial flow cylinder beam; the sixth-order modal frequency was $58.634 \mathrm{~Hz}$, and the vibration shape was the combination

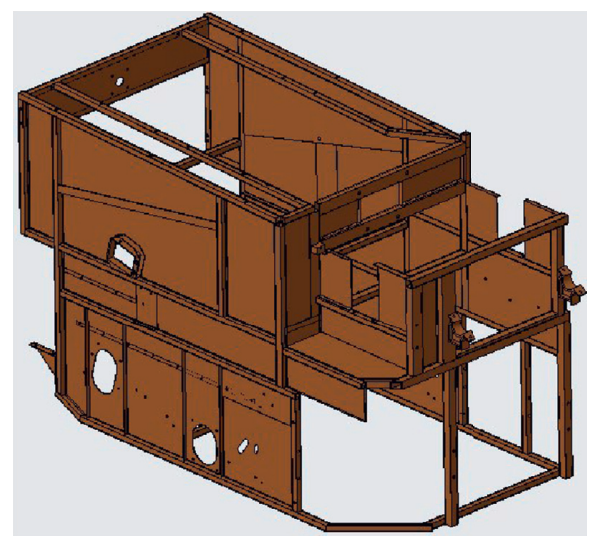

Figure 13: Optimized rack three-dimensional map.

of bending and torsion of the longitudinal axial flow cylinder beam.

The operation of engine, the stern of road, the vibration generated by the header, and the vibration generated by the rotating parts caused an excitation frequency to the rack [30]. The engine had the most serious impact, and the formula for calculating the excitation frequency was as follows:

$$
f_{1}=\frac{2 n_{1} z}{60 \tau},
$$

where $f_{1}$ is the excitation frequency, $\mathrm{Hz} ; Z$ is the number of engine cylinders; $n_{1}$ is the rated speed, $\mathrm{r} / \mathrm{min}$; $\tau$ is the number of engine strokes.

The engine of the crawler combine harvester is a fourcylinder four-stroke engine with a rated speed of $2400 \mathrm{r} / \mathrm{min}$. Based on the above data, the excitation frequency generated by the engine was $80 \mathrm{~Hz}$. Comparing it with the natural frequency of the first six steps of the threshing rack, it was found that the natural frequency of the rack was staggered by the excitation frequency of the engine, so there was no resonance phenomenon; that is, the optimized rack meets the requirements [31].

The modal parameters of the threshing rack were obtained by using the admittance element method [32]. Extract the first 6 modes of natural frequencies and modes within $10 \mathrm{~Hz}-60 \mathrm{~Hz}$. The first 6th-order damping ratios were 1.21 , $0.65,1.82,0.52,0.57$, and 0.27 , and the maximum value was 1.82 , which was consistent with the assumption that the damping is zero. The modes of each mode were shown in Figure 15.

According to the simulation mode and test modal results of the threshing rack of the combine harvester, the statistical and error analysis of the six test modes and simulation modes of the combine harvester threshing rack were carried out. Substituting the data of Table 5 into equation (9) can obtain the difference and percentage error of the simulation mode and the test mode, and the result was shown in Figure 16.

Origin is a professional drawing and data analysis software developed by OringinLab [33]. It is a graph visualization and data analysis software with easy learning and 


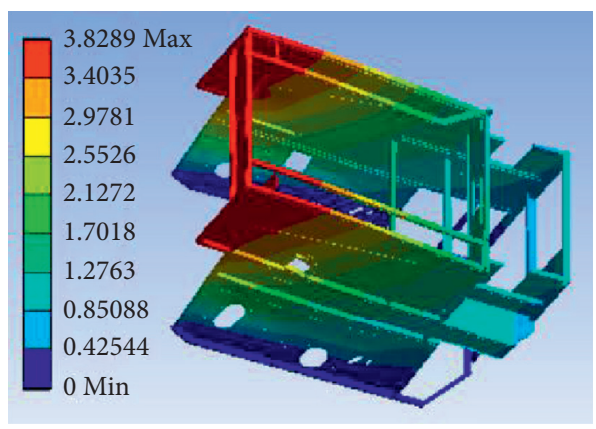

(a)

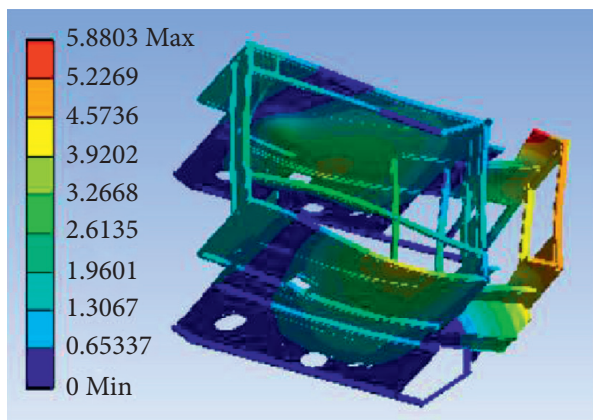

(c)

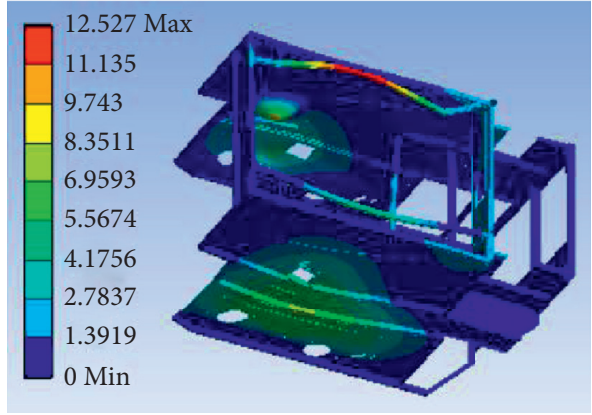

(e)

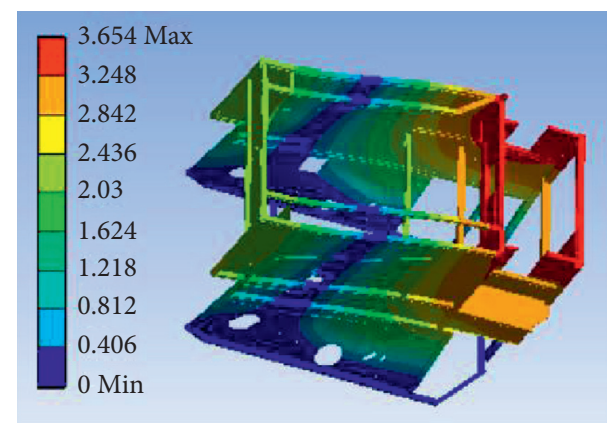

(b)

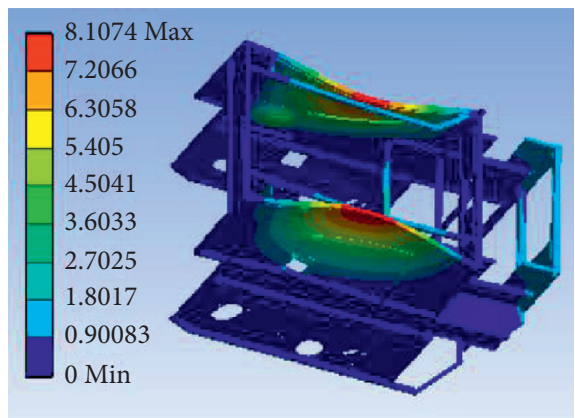

(d)

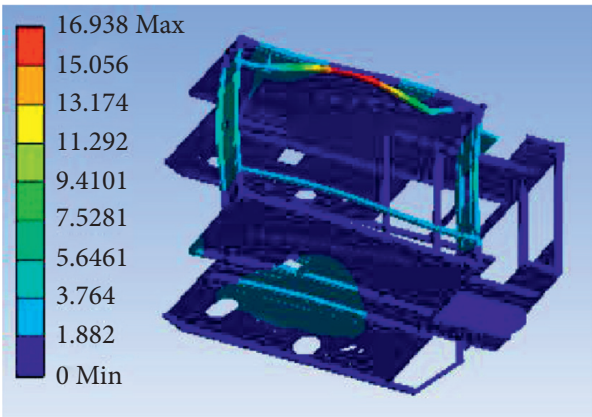

(f)

FIgURE 14: The six modes of the vibration mode of the rack. (a) 1st-order mode (16.476 Hz). (b) 2nd-order mode (27.913 Hz). (c) 3rd-order mode $(35.426 \mathrm{~Hz})$. (d) 4th-order mode $(45.523 \mathrm{~Hz})$. (e) 5th-order mode $(56.366 \mathrm{~Hz})$. (f) 6th-order mode $(58.634 \mathrm{~Hz})$.

flexible and other characteristics, which brings about convenience to engineers for data analysis and chart drawing. According to the results of the first 6-stage simulation mode and test mode of the combine harvester threshing rack, the order of each stage was the abscissa; the simulation mode and the test mode frequency were, respectively, plotted on the ordinate. The changes and comparisons of the simulation and test modes are shown in Figure 16.

It can be seen from Table 5 and Figure 16 that the natural frequencies obtained by the two analysis methods had the largest error rate in the fifth order. The error rate was $5.58 \%$ $<8.00 \%$. Therefore, it can be considered that the natural frequencies of each order obtained by the simulation modal analysis and the test modal analysis were highly consistent. The accuracy of the Finite Element Model was verified, which could be used for further structural optimization. In order to further improve the accuracy of the results, the results of the fifth-order mode of the threshing rack were analyzed separately. The fifth-order simulation mode and the test mode shape of the combine harvester threshing rack are shown in Figure 17.

It can be seen from Figure 17 that the mode shape of the test mode and the calculated mode had a certain degree of difference when the natural frequency error rate is maximum. On the one hand, the degree of freedom of the three-dimensional model of the two analysis methods was inconsistent, and the number of degrees of freedom of the model of the simulation modal analysis was more than that of the test modal model. On the other hand, Finite Element Modal analysis used bonded contacts to simulate the welding relationship of mechanical structures, which caused errors. In addition, the Finite Element Modal analysis generally did not consider the damping of the structure and the number of measuring points of the test modal cannot be the actual size of the reaction mechanism. 


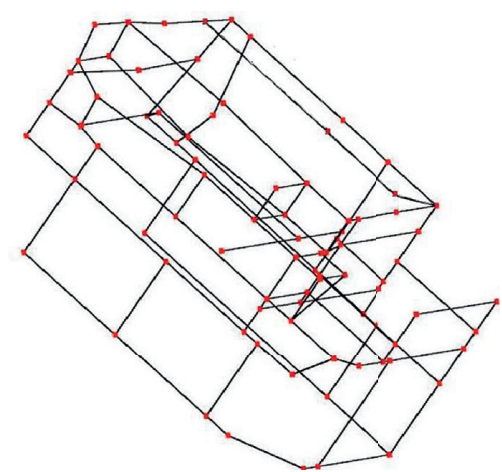

(a)

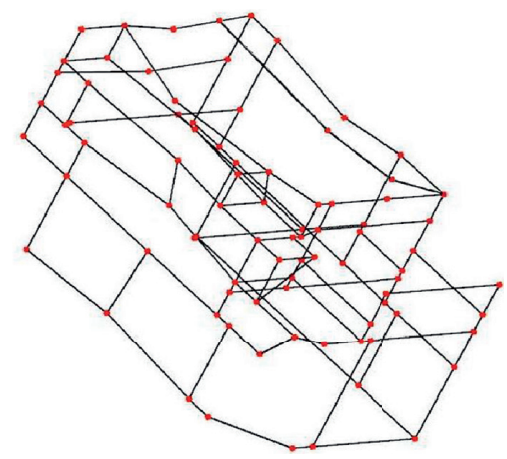

(d)

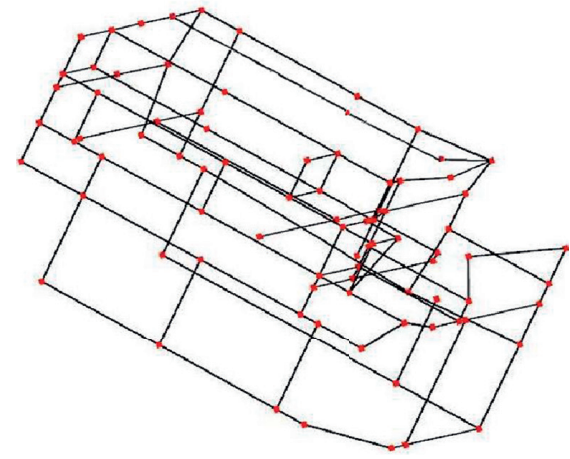

(b)

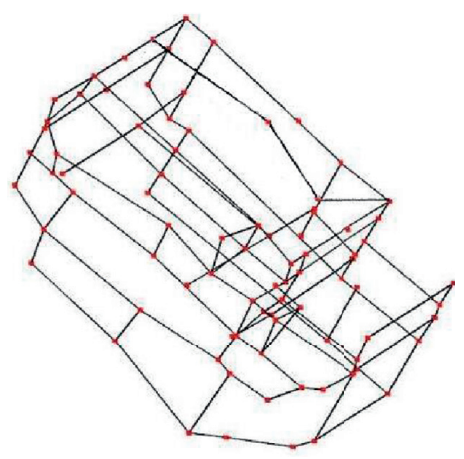

(e)

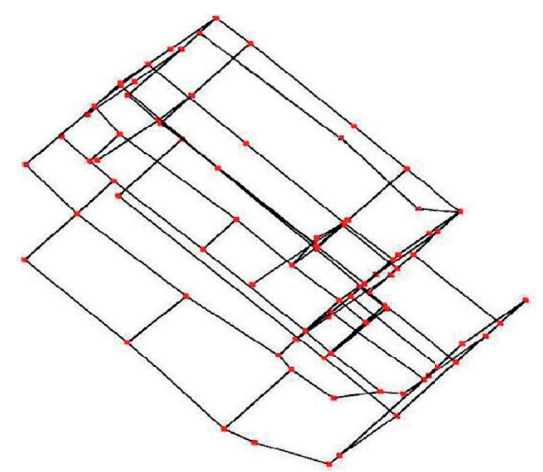

(c)

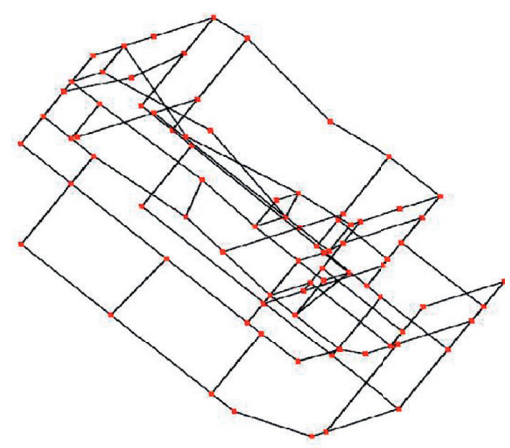

(f)

Figure 15: Test mode of the threshing rack. (a) 1st-order mode shape diagram. (b) 2nd-order mode shape diagram. (c) 3rd-order mode shape diagram. (d) 4th-order mode shape diagram. (e) 5th-order mode shape diagram. (f) 6th-order mode shape diagram.

TABle 5: Comparison of simulation and test modal frequency.

\begin{tabular}{lcccc}
\hline \multirow{2}{*}{ Modal order } & \multicolumn{2}{c}{ Natural frequency $(\mathrm{Hz})$} & Difference $(\mathrm{Hz})$ & Percentage error $(\%)$ \\
\hline 1 & Simulation mode & Test mode & 0.190 & 1.15 \\
2 & 16.476 & 16.286 & 1.367 & 4.89 \\
3 & 27.913 & 26.546 & 1.179 & 3.33 \\
4 & 35.426 & 34.247 & -1.859 & 4.08 \\
5 & 45.523 & 47.382 & 3.148 & 5.58 \\
6 & 56.366 & 53.218 & 2.092 & 3.57 \\
\hline
\end{tabular}

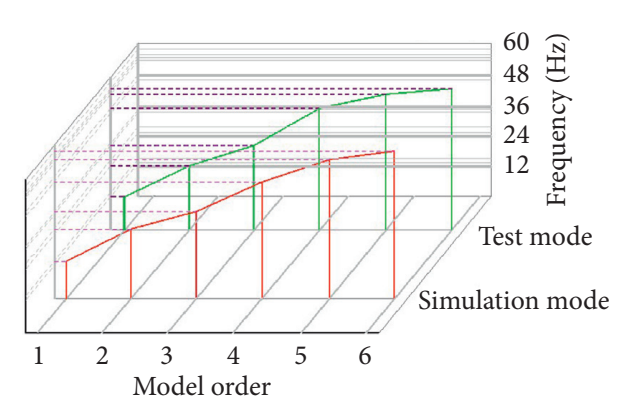

FIgURE 16: Comparison of threshing rack simulation and test modal.

3.4. Optimization Effect Verification. Based on the above calculation and simulation modal analysis, the physical object was processed on the basis of the feasibility of the optimization idea, and then the physical comparison was performed to verify the optimization effect. The original rack and the optimized rack structure are shown in Figure 18.

Through the static simulation and structural topology optimization, the inclined cut longitudinal flow threshing rack was obtained, which reduced the overall weight under the condition of bearing strength and rigidity. Figure 19 shows the weight comparison test before and after rack optimization [34].

Through the analysis of the test results, after the optimized design of the threshing rack, the rack quality was reduced from $261 \mathrm{~kg}$ to $225 \mathrm{~kg}$, and the weight was $13.7 \%$ less than the original rack. The weight reduction effect was obvious. The dimensions of the threshing and cleaning rack have also been optimized to reduce the width of the rack and make the entire mechanism more compact. The specific dimensions are shown in Figure 20. 


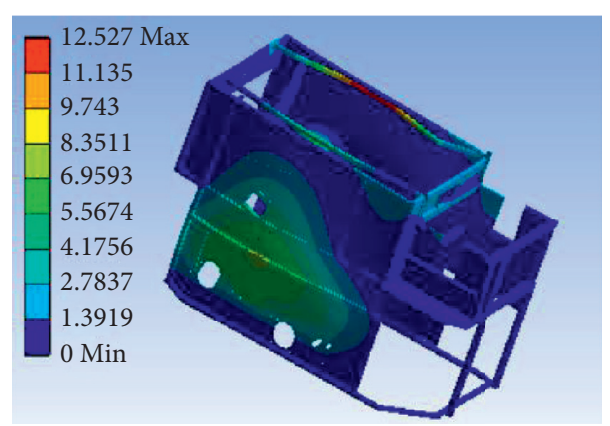

(a)

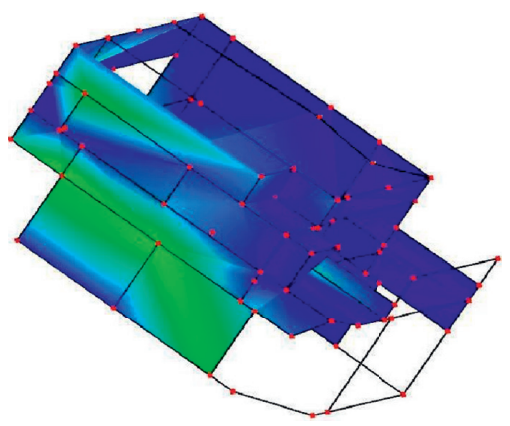

(b)

FIgURe 17: Comparison of the 5th-order simulation and test mode shape of the threshing rack. (a) Simulation mode. (b) Experimental modal.

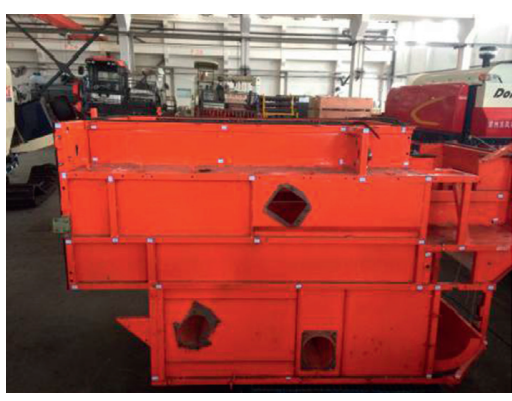

(a)

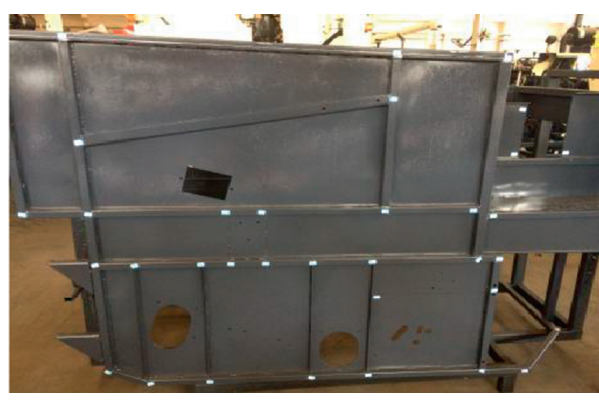

(b)

FIgURE 18: Rack structure comparison chart. (a) Original threshing rack structure. (b) Modal optimized threshing rack structure.

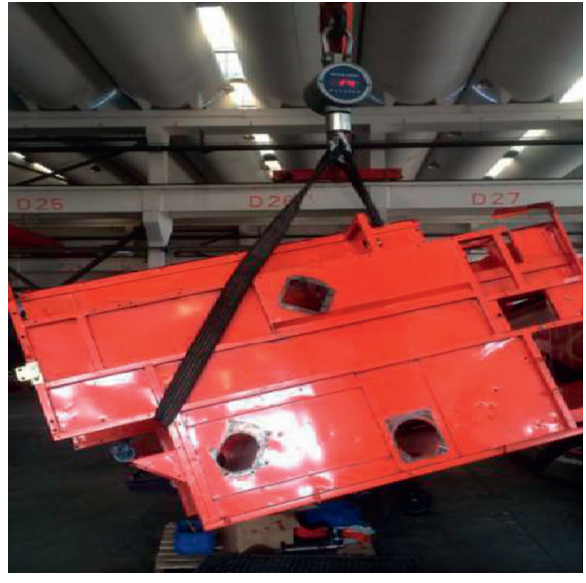

(a)

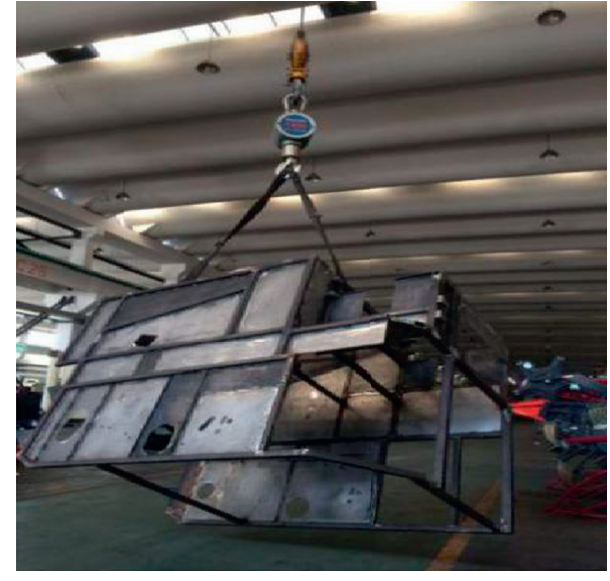

(b)

FIGURE 19: Quality comparison test before and after optimization of threshing rack of combine harvester. (a) Original threshing rack weighing. (b) Optimized threshing rack weighing.

In order to further verify the effect of the rack optimization, after the working parts were assembled on the rack, the whole machine was subjected to modal test (shown in Figure 21(a)). By arranging the modal measuring points of the threshing rack structure on the whole machine threshing rack, the modal value of the threshing rack in the assembled state was tested, and the modal structure of the threshing cylinder assembled on the whole machine was obtained. The threshing rack on the combine harvester was extracted and the block structure of the threshing rack was established. The result was shown in Figure 21(b). 


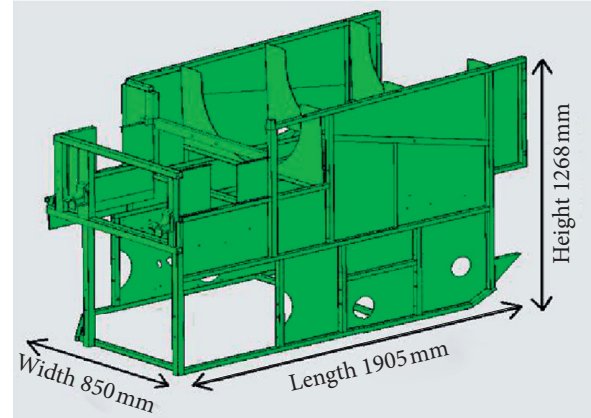

(a)

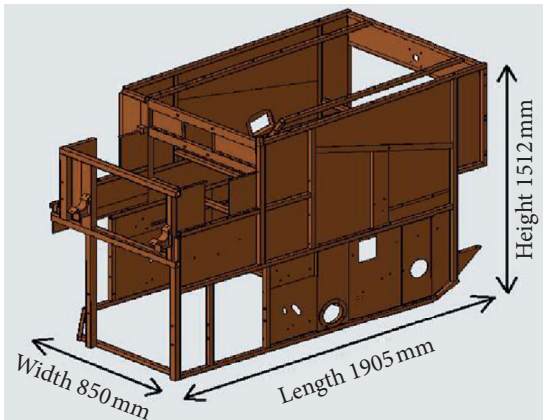

(b)

FIgURE 20: Rack size optimization. (a) Rack size before optimization. (b) Rack size after optimization.

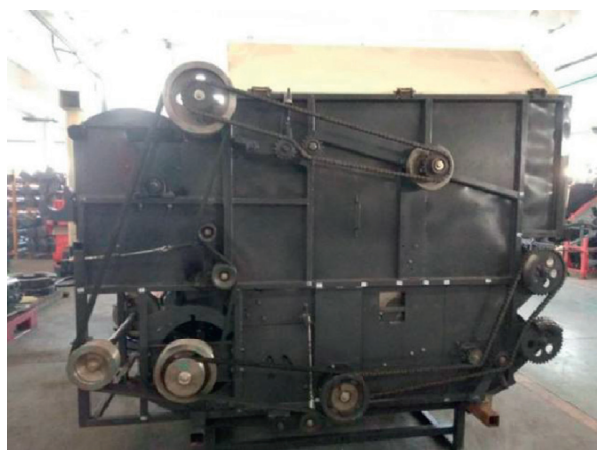

(a)

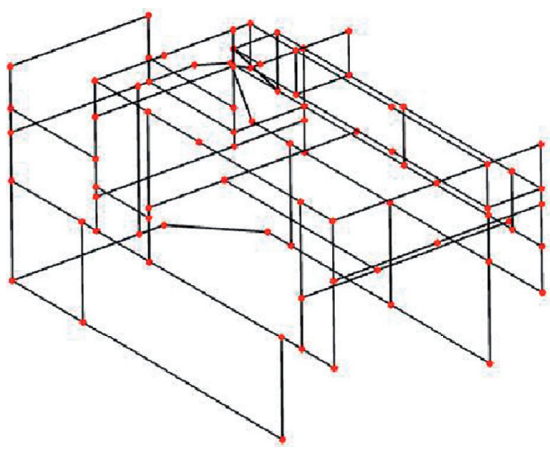

(b)

FIGURE 21: Structure of the combine harvester threshing rack assembly. (a) Threshing rack assembly status. (b) Block diagram of the threshing rack.

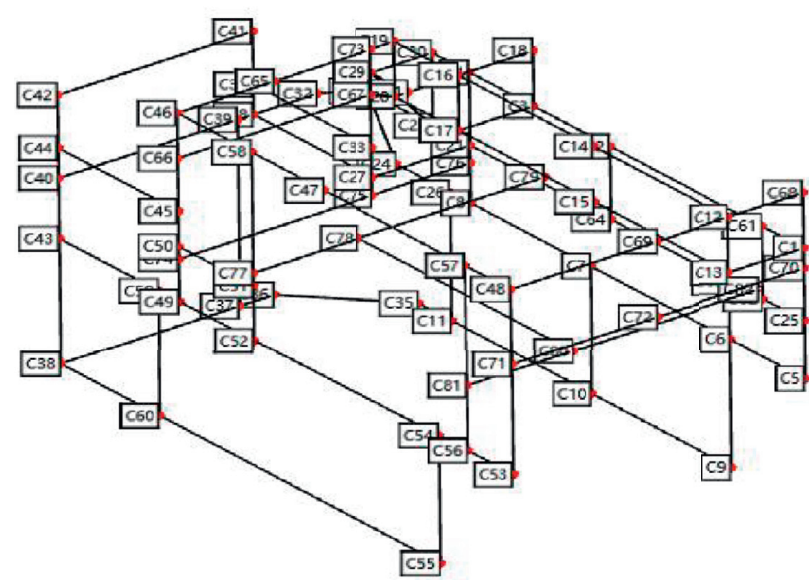

(a)

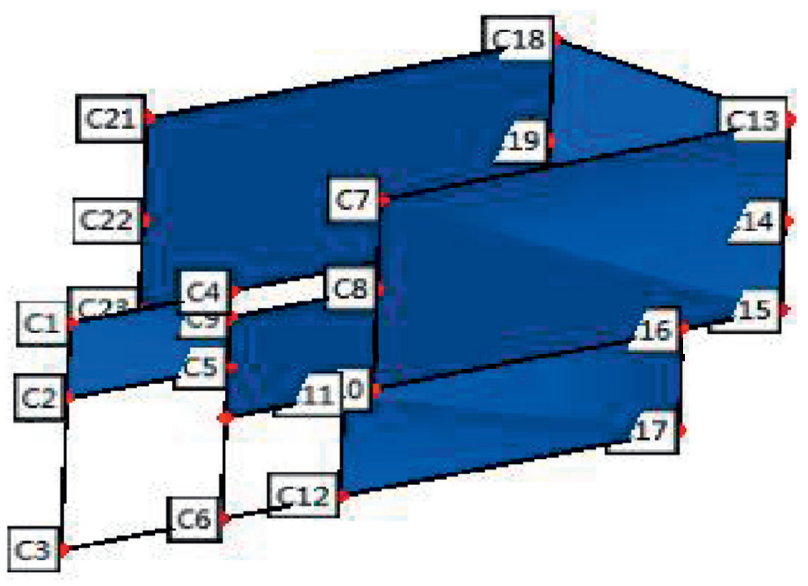

(b)

FIGURE 22: Block diagram of the threshing rack and measuring points. (a) Structural model of the threshing rack. (b) Measuring point distribution of the threshing rack.

The block structure of the threshing rack of the combine harvester had 82 structural points, as shown in Figure 22(a). It was difficult to perform sensor placement and vibration testing at all points in the assembly state of the threshing rack. Therefore, 23 points representing the contour state of the threshing rack were selected for vibration testing and modal analysis. The modal test points of the threshing rack were shown in Figure 22(b).

Acceleration sensors were arranged in batches at 23 points on the threshing rack. By selecting the 5 th point as the hammer excitation point and distributing the vibration signal of each point, the representative points 1,4 , and 10 


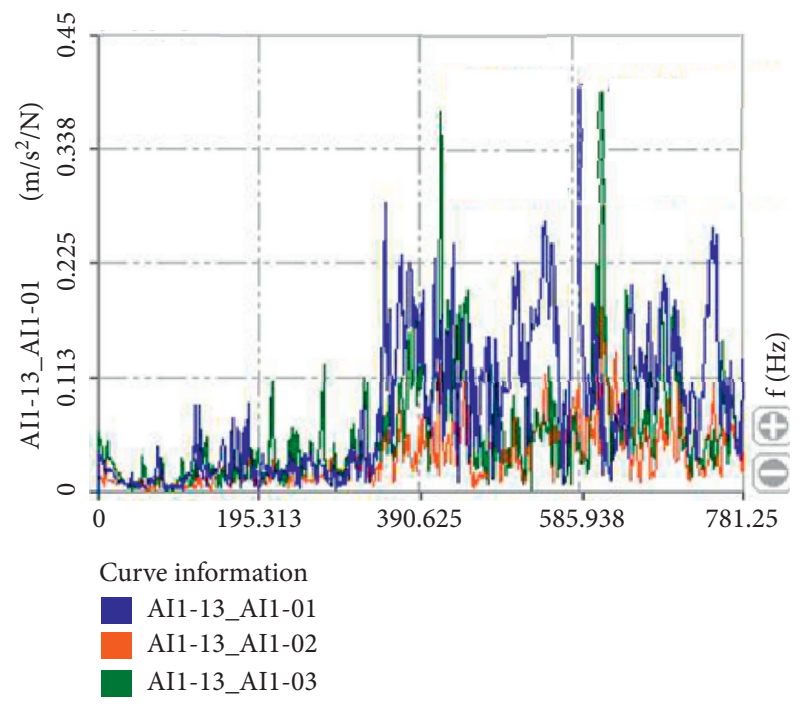

(a)

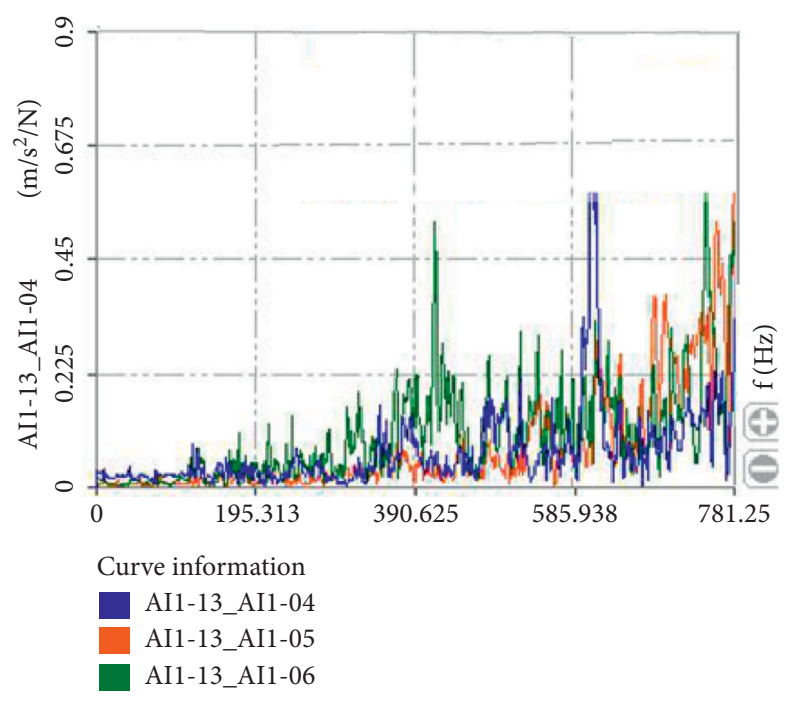

(b)

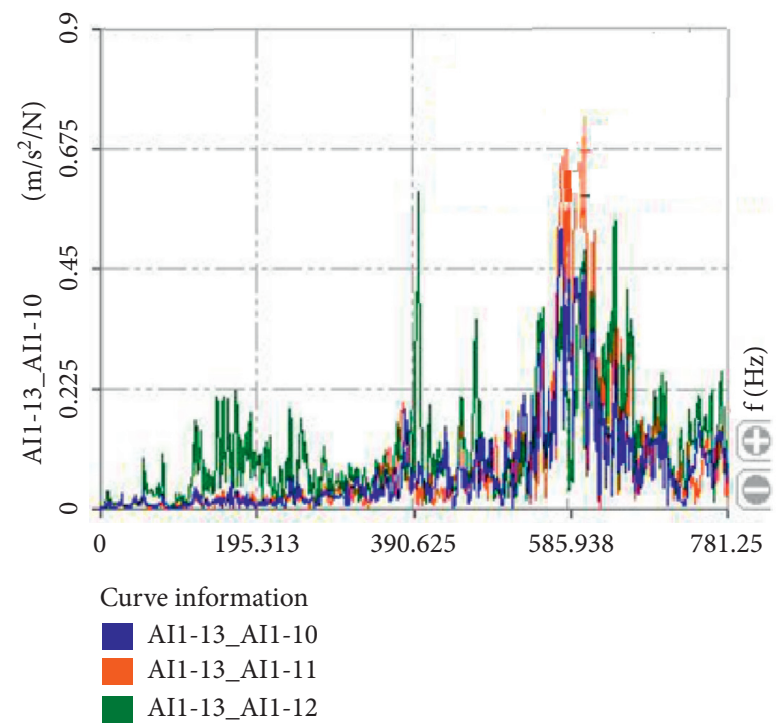

(c)

Figure 23: Frequency response curve on the threshing rack. (a) Measuring point 1. (b) Measuring point 4. (c) Measuring point 10.

were selected. The frequency response curve is shown in Figure 23.

The modal frequency and the mode shape were calculated by the peak extraction method, and the calculated modal parameters were saved. The first six calculation results of the modal frequency were $32.510,56.831,78.445,100.370$, 117.548 , and $131.273 \mathrm{~Hz}$. The mode of the modal emptyloaded threshing rack of the threshing rack after assembly was 2 3 times larger, and the test result was larger than the simulation result, which better avoided the working frequency of the components on the harvester and the resonance phenomenon.

After the assembly of the threshing rack was completed, the modal analysis was carried out. The first 6 -order mode shape of the assembled threshing rack is shown in Figure 24 .
It can be seen from Figure 24 that the modal of the assembled threshing rack of the test was the threshing machine face mode, that is, the connecting plate on the side of the threshing rack and the inner supporting structure. The mode shape was mainly on the outside of the threshing rack. This place was also a weak point where the threshing rack supports less and was weak, which provided reference for further optimization. The working frequency of the combine harvester parts in Table 1 was plotted as a histogram, and then the 6th-order natural frequency of the test mode of the no-load rack (from left to right, the first order to the sixth order) and the first-order natural frequency of the whole assembly rack were drawn into a histogram. The result is shown in Figure 25.

It can be seen from Figure 25 that since the rack was mainly driven by a rotating component, the excitation 


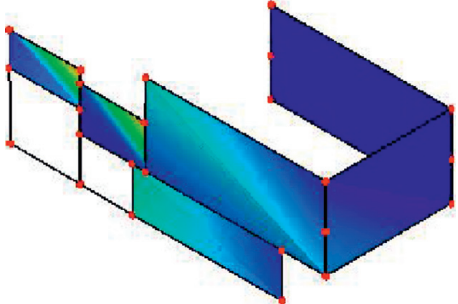

(a)

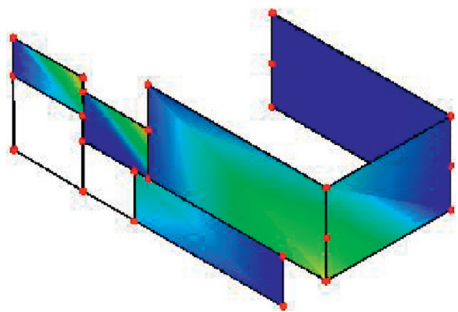

(d)

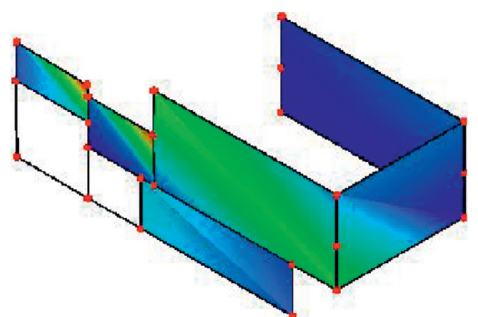

(b)

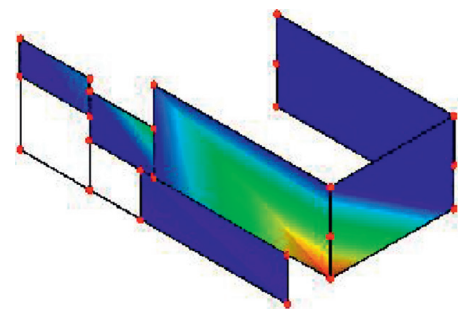

(e)

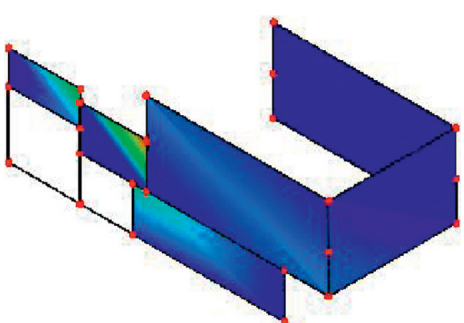

(c)

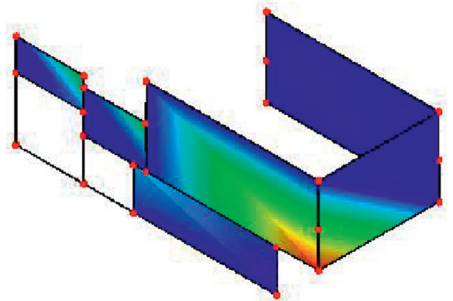

(f)

FIGURE 24: The first 6-order mode shape of the assembled threshing rack. (a) 1st order. (b) 2nd order. (c) 3rd order. (d) 4th order. (e) 5th order. (f) 6th order.

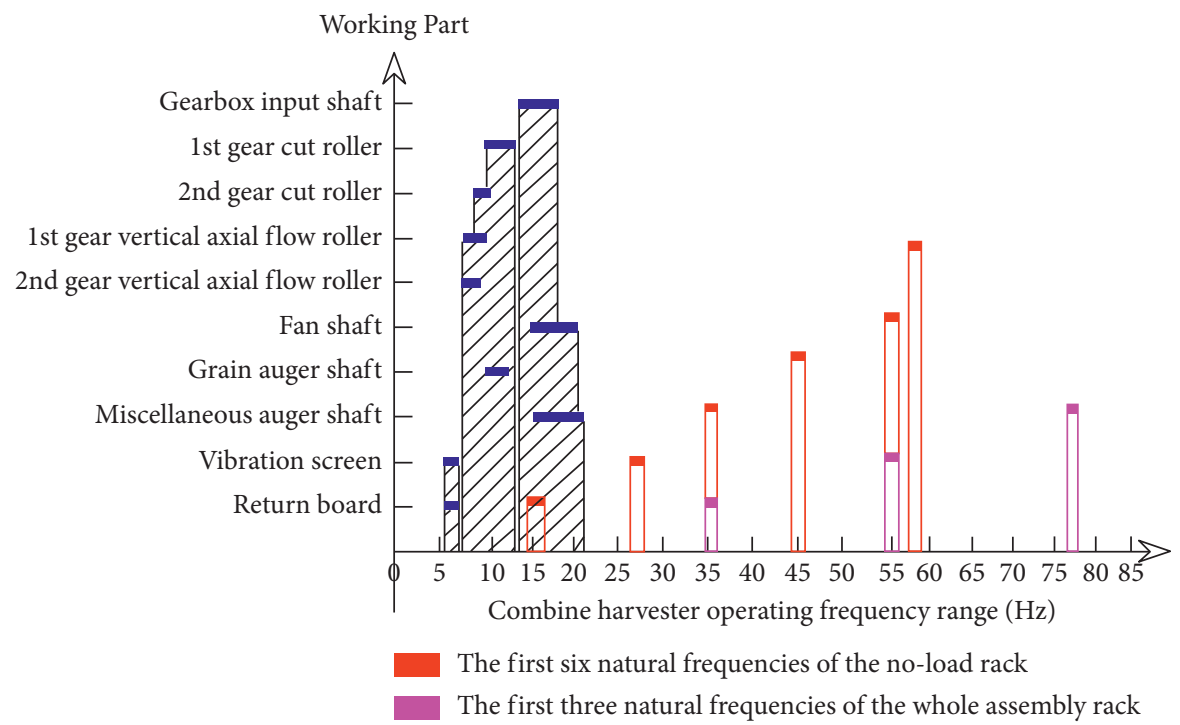

FIgURE 25: Comparison of the natural frequency and excitation frequency of the rack.

frequency generated during operation was the main external excitation source. The vibration excitation frequency of the vibrating screen and the returning plate of the combine harvester was $5.78 \sim 7.22 \mathrm{~Hz}$, the excitation frequency of the auger of the header was $10.94 \sim 21.12 \mathrm{~Hz}$, and the excitation frequency of the longitudinal flow roller was 7.46 13.17 Hz. The excitation frequency of the input shaft and fan shaft was $14.24 \sim 20.10 \mathrm{~Hz}$, which was mainly distributed at $5.78 \sim 20.10 \mathrm{~Hz}$.

Regarding the modal analysis of the rack, the maximum error of the calculated modal and test modes was $5.58 \%$ and less than $8 \%$. It can be considered that the natural frequencies of the various stages obtained by the simulation and the test modal analysis were highly consistent. The accuracy of the Finite Element Model was verified. The natural frequencies of the 6 th order before the test mode increase gradually with the increase of the order. The range of the first 6 natural frequencies was between 16.476 and $58.634 \mathrm{~Hz}$, and there was only a small amount of coupling resonance with the excitation frequency of the working part. After assembling the threshing rack machine, the test modal analysis was carried out, and the six natural frequencies were also taken, mainly distributed at $32.510 \sim 131.273 \mathrm{~Hz}$, and the natural frequency maximum was about 10 times of the average value of the excitation frequency. It can be seen that the natural frequency of the assembly state of the whole 
machine was about $2 \sim 3$ times that of the single threshing rack and the excitation of the working parts was completely avoided. In summary, the excitation frequency of the main working components of the threshing device and the natural frequency of the rack were better staggered, which effectively avoided the occurrence of resonance phenomenon, indicating that the optimized design of the rack can meet the working requirements.

\section{Conclusions}

(1) Through the static simulation analysis of the racktype rice combine harvester threshing rack, the maximum equivalent stress of the rack was $170.82 \mathrm{MPa}$, and the allowable stress value less than Q235A was $195 \mathrm{MPa}$, which was in accordance with the stiffness and strength conditions. The stress value of each main component of the entire frame is far less than the maximum value, so the structure fully meets the load-bearing requirements, and the structure and size can be further optimized to effectively reduce the cost. The maximum equivalent strain solution was $0.81 \mathrm{~mm}$, which was distributed on the left side of the longitudinal axis flow roller support beam.

(2) Through the modal analysis of the rack, the maximum error of the calculated modal and test modes was $5.58 \%$ and less than $8 \%$. It can be considered that the natural frequencies of the various stages obtained by the simulation modal analysis and the test modal analysis were highly consistent. As a result, the accuracy of the Finite Element Model was verified. The excitation frequency generated by the working parts on the combine harvester avoids the first 6 natural frequencies of the optimized rack and did not resonate with the rack. It provided a good theoretical basis for the subsequent research and improvement of the threshing rack.

(3) The total weight of the rack under the condition of static strength and deformation was reduced by $13.7 \%$, and the weight reduction effect is obvious. The dimensions of the threshing and cleaning rack have also been optimized to reduce the width of the rack and make the entire mechanism more compact. The modal test results after the assembly of the rack was optimized. The modal of the whole machine was $2 \sim 3$ times that of the single rack. The test results were larger than the simulation results and meet the optimization requirements.

\section{Data Availability}

The data used to support the findings of this study are available from the corresponding author upon request.

\section{Conflicts of Interest}

The authors declare that they have no conflicts of interest.

\section{Acknowledgments}

This research work was supported by the Jiangsu Province "Six Talents Peak" High-level Talent Project (GDZB-085), the National Natural Science Foundation of China (51705212), Open Fund of Jiangsu Key Laboratory of Agricultural Equipment and Intelligent High Technology (JNZ201912), Jiangsu Province Postgraduate Research and Innovation Project (KYCX20_3086), and a project funded by the Priority Academic Program Development of Jiangsu Higher Education Institutions (no. PAPD-2018-87).

\section{References}

[1] Z. Tang, Y. Li, X. Li, and T. Xu, "Structural damage modes for rice stalks undergoing threshing," Biosystems Engineering, vol. 186, pp. 323-336, 2019.

[2] Y. J. Jiang, Y. T. Liao, C. Qin, Z. Y. Guan, and Q. X. Liao, "Vibration analysis and improvement of 4SY-2.9 type rapeseed windrower rack," Transactions of the Chinese Society of Agricultural Engineering, vol. 33, no. 9, pp. 53-60, 2017.

[3] X. L. Zhu, Y. F. Zhang, Z. W. Pan et al., "Study on the natural vibration characteristics of F2 rack and transmission system of 1580 hot strip mill," Metallurgical Equipment, vol. 2, pp. 1-7, 2018.

[4] M. G. Zhou, L. Zhang, Y. Chen, M. Y. Liu, and Y. P. Huang, "Optimization design of ship tractor rack structure based on sensitivity analysis," Transactions of the Chinese Society of Agricultural Engineering, vol. 32, no. 12, pp. 54-60, 2016.

[5] X. F. Guo, W. B. Wang, S. L. Guo, and S. J. Chen, "Modal analysis and experimental research on potato harvester rack," Mechanical Design \& Manufacturing, vol. 7, pp. 154-157, 2018.

[6] K. M. Bajoria, K. K. Sangle, and R. S. Talicotti, "Modal analysis of cold-formed pallet rack structures with semi-rigid connections," Journal of Constructional Steel Research, vol. 66, no. 3, pp. 428-441, 2010.

[7] W. Fiebig and J. Wróbel, "Two stage vibration isolation of vibratory shake-out conveyor," Archives of Civil and Mechanical Engineering, vol. 17, no. 2, pp. 199-204, 2017.

[8] J. Park, J. Lee, S. Ahn, and W. Jeong, "Reduced ride comfort caused by beating idle vibrations in passenger vehicles," International Journal of Industrial Ergonomics, vol. 57, pp. 7479, 2017.

[9] W. Zhang, Optimization Design and Modal Analysis of Key Components of the Bottom Machine, Lanzhou Jiaotong University, Lanzhou, China, 2017.

[10] Y. P. Zhang, Z. C. Hu, Z. Y. You, F. Q. Gu, and F. Wu, "Modal analysis and vibration test of 4 HCDS-100 peanut harvester rack," Jiangsu Agricultural Sciences, vol. 46, no. 24, pp. 244247, 2018

[11] Z. Tang, X. Y. Li, X. D. Chen, and Y. Chen, “Design of negative pressure spiral feeding device for tangential and longitudinal axial intersection of combine harvester," Advances in Materials Science and Engineering, vol. 2019, Article ID 1647230, 12 pages, 2019.

[12] H. H. Lee, Finite Element Simulations with ANSYS Workbench 18, SDC Publications, Mission, KS, USA, 2018.

[13] H. P. Fan, K. P. Zhang, B. G. Sun, and Q. Chai, "Modal analysis and structure optimization of wheat harvester rack under maize/wheat intercropping model," Chinese Journal of Agricultural Mechanization, vol. 39, no. 5, pp. 15-20, 2018. 
[14] J. Li, G. H. Zhao, Q. X. Huang, L. F. Ma, C. X. Zhi, and M. H. Cheng, "Experimental analysis of rolling compounding of Q235A extra heavy plate," Hot Working Technology, vol. 46, no. 23, pp. 115-117, 2017.

[15] Z. Tang, H. T. Zhang, Y. P. Zhou, and Y. Li, "Effects of stem cutting in rice harvesting by combine harvester front header vibration," Advances in Materials Science and Engineering, vol. 2019, Article ID 6834269, 15 pages, 2019.

[16] G. Huang, H. Wang, and G. Li, "A novel multi-grid assisted reanalysis for re-meshed finite element models," Computer Methods in Applied Mechanics and Engineering, vol. 313, pp. 817-833, 2017.

[17] J. Zhang, "Limited analysis and optimization of automotive heatsink based on ANSYS," Electronic Test, vol. 16, pp. 53-55, 2017.

[18] M. H. Pu, F. Y. Wang, and W. Yu, "Research on boundary conditions of template finite element analysis of injection molding machine based on HyperWorks," Mechanical Design and Research, vol. 34, no. 6, pp. 156-160, 2018.

[19] S. R. Chen, Y. P. Zhou, Z. Tang, and S. N. Lu, "Modal vibration response of rice combine harvester frame under multi-source excitation," Biosystems Engineering, vol. 194, pp. 176-195, 2020.

[20] W. Feng, Y. L. Pang, P. Li, J. B. Cui, X. F. Zhang, and X. M. Zhan, "Study on optimization design of small harvester rack based on ISIGHT," Southwest Agricultural Journal, vol. 32, no. 1, pp. 174-178, 2019.

[21] L. J. Wang, W. Wang, Y. X. Du, L. Xu, W. C. Huang, and J. X. Liu, "Modal analysis and topology optimization of hydraulic machine rack based on ANSYS-workbench," Coal Mine Machinery, vol. 40, no. 3, pp. 79-83, 2019.

[22] T. Stolarski, Y. Nakasone, and S. Yoshimoto, Engineering Analysis with ANSYS Software, Butterworth-Heinemann, Oxford, UK, 2018.

[23] X. W. Li, C. Tian, and C. Wang, "Research on a method of modal test placement for automobile seats," Times Automobile, vol. 6, pp. 130-131, 2018.

[24] T. F. Ding, B. Li, and J. W. Wang, "Free modal simulation analysis and experimental modal study of drill tower," Mining Machinery, vol. 7, pp. 15-19, 2016.

[25] J. Garcia-Manrique, D. Camas-Peña, J. Lopez-Martinez, and A. Gonzalez-Herrera, "Analysis of the stress intensity factor along the thickness: the concept of pivot node on straight crack fronts," Fatigue \& Fracture of Engineering Materials \& Structures, vol. 41, no. 4, pp. 869-880, 2018.

[26] H. Ghasemi, H. S. Park, and T. Rabczuk, "A level-set based IGA formulation for topology optimization of flexoelectric materials," Computer Methods in Applied Mechanics and Engineering, vol. 313, pp. 239-258, 2017.

[27] H. Ghasemi, H. S. Park, and T. Rabczuk, "A multi-material level set-based topology optimization of flexoelectric composites," Computer Methods in Applied Mechanics and Engineering, vol. 332, pp. 47-62, 2018.

[28] L. Zhong, J. W. Lei, Z. Y. Lei, and J. Deng, "Optimization design of cleaning wheel for monitoring device based on ANSYS," Journal of Nanhua University (Natural Science), vol. 33, no. 2, pp. 33-39, 2019.

[29] R. M. Toyabur, M. Salauddin, H. Cho, and J. Y. Park, "A multimodal hybrid energy harvester based on piezoelectricelectromagnetic mechanisms for low-frequency ambient vibrations," Energy Conversion and Management, vol. 168, pp. 454-466, 2018.

[30] S. Y. Lou, Analysis and Experimental Study on Vibration Characteristics of 3WQF80-10 Oil-Powered Unmanned
Helicopter Rack, Chinese Academy of Agricultural Sciences, Beijing, China, 2018.

[31] S. H. Yang, J. K. Chen, and Z. P. Yin, "Structural design of rack natural frequency optimization," Mechanical Design and Manufacturing, vol. 10, pp. 71-73+77, 2018.

[32] Z. He, W. Tang, T. Lin, and Z. S. Shi, "Modal analysis and an experimental study into a marine gearbox featuring confluence transmission," Transactions of FAMENA, vol. 42, no. 4, pp. 43-52, 2019.

[33] X. Zhang, Y. Li, and W. Sun, "Application of computer-based drawing software origin in chemical basic experiments," Guangdong Chemical Industry, vol. 45, no. 11, pp. 264-265, 2018.

[34] Y. J. Song and E. S. Jeon, “Optimal design of lightweight seat extension equipment using topology optimization and design of experiment," International Journal of Applied Engineering Research, vol. 12, no. 9, pp. 1855-1859, 2017. 